\title{
Study of Female Narration in Yang Jiang's Literary Works
}

\author{
Xue Han \\ Department of Arts and Sciences Jilin Agricultural Science and Technology College, Jilin, Jilin 132101
}

Keywords: Yang Jiang; Literary Works; Female Narration

\begin{abstract}
As a woman, Yang Jiang has done her job in the trinity role of creation, translation, and literary theory research. She has performed brilliantly in her role as a daughter, wife, and mother and has become the most virtuous wife in the eyes of Qian Zhongshu. How did Yang Jiang succeed in the dilemma of the common cause and family as a modern intellectual woman? After her husband and daughter had left her, what power did support her in the year when she had entered Mi Kui? Texts such as "Our Benevolence" and "Being on the edge of life", which have both emotional and intellectual qualities, mainly from the feminist perspective interpret the awakening of feminine consciousness embodied in her life practices and creative activities by Yang Jiang and women. The reconstruction of female identity seeks to resolve this doubt.
\end{abstract}

\section{Introduction}

Yang Jiang is a unique and beautiful landscape in the history of Chinese literature in the century. She was born in a scholarly family from generation to generation, and also studied for Qian Zhongshu, a master of glorious Chinese culture. She has a long history of scholarly scholarship and is well-versed in many fields such as prose, drama, fiction, translation, and literary theory. His plays "Ruyi Xinyi" and "Making Reality Perfect" promoted the maturity of modern drama in China. The playwright Li Jianwu once commented that in the history of modern Chinese comedy development, "the first epochal monument belongs to Zhu Dingxi Lin, who As we all know, in the second, I would like to point out joyously, that is, Ms. Yang Jiang." His translations of “The Little Era” and "Don Quixote" are highly acclaimed and provide solid and rigorous ideas for cultural exchange between China and foreign countries. Achievements. His literary theories of "Chunjiji" and "About the Novel" show her creations and gains in the field of literary studies. Her appreciation of Fielding, Sacre, and Austin's creations made people see that Yang Jiang was receiving Chinese traditions. The other side of cultural influences is the baptism of Western culture. His essays "Ji-Yuan Liu Yi Ji" and "Drinking Tea" describe the life and life sentiments in a particular history as the wise man's tone, which is well known as a representative of scholar's prose. His novel "Bathing" vividly portrays the sentient beings of a generation of intellectuals and has become an important work to display the spiritual history of intellectuals, which has aroused widespread concern in the academic world [1]. In the new century, Yang Jiang, who had entered the year of Mi Kui, was still unable to write. He created "Our Benevolence" and "Getting to the Edge of Life" and translated and published the "Fido-Plato dialogue record", again causing readers and critics to Yang Jiang's attention. Yang Jiang can play a role in the trinity of creative writing, translation, and literary theory studies, fully demonstrating her elegant style of intellectual women. Yang Jiang has been involved in the literary world since the 1930s and has experienced nearly 80 years of creative career. Her research has continued. Especially since the 1980s, more and more attention has been paid to the female literati behind this cultural Kunlun. , Yang Jiang research hot. On the basis of previous research, Yang Jiang has produced a large number of research results in the field of research. Scholars have provided many research perspectives and viewpoints [2]. They have achieved remarkable results in their novels, prose, comedy, and comprehensive research. A large number of monographs have appeared in endlessly. Enhance the overall level of Yang Jiang's research field. Yang Jiang's research has obviously become a case that cannot be ignored in the history of modern Chinese literature. 


\section{Female Consciousness Accumulation and Awakening}

The background of a writer's time, the family education he received at a young age, and the cultural imperfection he suffered during his studies will inevitably affect his aesthetic orientation and his writing style, thus affecting his artistic creation. Yang Jiang was born at Shuxiangmendi. He had good family enlightenment. He had enlightenment in his early childhood. When he felt religious feelings, he studied Soochow Qinghua, trained a solid academic foundation, and then studied in Oxford and Paris, absorbing the cultural spirit of Western freedom. The cultural influence these young people experienced had exerted a subtle influence on Yang Jiang's attitude to life and literary creation. Not only is it nourished by the milk of traditional Chinese culture, but it is also accompanied by the dew of modern Western culture. With the help of the New Culture Movement and the Women's Liberation Movement, Chinese intellectuals can begin to freely breathe the fresh air of democracy and openness which makes Yang Both the graceful bearing of the intellectuals, the lasciviousness of the traditional women, and the independent consciousness of the Western humanistic spirit are reflected in the transformation of the feminine consciousness and the reconstruction of female identities. Since the mother-centered matriarchal society was replaced by a male-centered patriarchal society, it has formed the patriarchal patriarchal rule. Since then, women have been exiled as marginal losers of history beyond the male rights culture. "In patriarchal societies, the dominant groups control reality through controlling speech. They deprive women of their right to speak and keep them silent for a long time. A silent group is bound to become a buried group." The history of mankind became a History of the absence of women. In the history of thousands of years in China, women's social identity as a "writer" has appeared very early, but women's creation has become an important part of literary creation and it is indeed a product of modern society. Viewing the history of Chinese literature, female writers can only be historically well-documented. Although there are ban yi hao, zhuo wen jun, and qing dynasty, more female writers are left behind in historical records. Compared with the brilliant male works created by the literary world, women's creations are no different than a drop in the ocean. The history of human literature is almost a male literary history. Men are the first creators of human literature, while women are writers in men's texts [3].

Then, how does this influence of Chinese and Western cultures translate into female consciousness in the works of Yang Xie? I will first analyze it by using the subtitle "Cai Weixi Fei” used by Yang Jiang in "Bathing". The uniqueness of the female consciousness that elicited Yang Jiang. "Cai Wei Cai Fei," pronounced the "Book of Songs • Valley Wind”, "This is a abandoned woman poetry," Cai Wei mining Philippine, without the following body," means that leaves do not root, metaphor love new people and abandoned old people. Yang Jiang's reference to the title of the abandoned woman verse in The Book of Songs can lead to multiple reflections. First of all, why did Yang Jiang choose to abandon women's verses? This can be seen by Yang Jiang's reflection on women's issues. She has a certain critique of Chinese traditional culture or the status of women in marriage in a masculine culture. The appearance of "Valley Wind" shows that women in ancient times were very weak in love and marriage and were forced to become victims of a man-centered society. Although the work does not explicitly condemn the negative emotions of men, it still has a profound warning effect from the initial confession of men to women. Yang Jiang used the language in The Book of Songs to criticize, both as a concern for traditional culture and as an examination of the unreasonable elements in traditional culture, with a certain sense of vigilance, corresponding to verses, and taking a shower. Du Lilin is faced with the problem of her husband's affair. It can be seen that Yang Jiang's concern about women's passive status as "abandoned women” in marriage. Second, the husband abandoned the married wife because of circumstances or lack of love. This is a social problem that has been reflected in the earliest poetry collection of the Book of Songs, such as "Wei Feng • Qi", and this The first "County/Wind Valley Wind" is also a poem for abandoned women. Why did Yang Jiang choose this one? It was also an abandoned woman's tone to tell her husband's abandonment of pain. Compared with "Yi", the woman in "Valley" was obviously As the temperament tends to be milder than the former, it must be absolutely decisive. When you recall the past and tell the feelings, it is more of a grudge rather than an anger. Let people read it with a sense 
of "drowning their misfortune, angering their indisputableness," from the artistic style. Seeing also better reflects the gentle and honest poetic tradition that Chinese Confucians claim. Yang Jiang chose to abandon the women's poems here and "Gu Feng” to abandon the "Death". It can be seen that Yang Jiang is deeply influenced by the Chinese Confucian tradition to pursue a gentle and honest style. Therefore, the prominent female consciousness in Yang Jiang's works makes us more What many feel is a critique hidden behind mild language, rather than a sharp subversive break.

\section{Reconstruction of Female Identity}

In ancient societies that rely on human reproduction for their livelihood, "in order to ensure the proliferation of family tribes, the most important exchange and circulation of 'articles' is a woman. With this kind of blood as the material basis, it extends out of the male-centered culture and politics. Religion... "Women are the existence of exchanging goods, but they are only used as a kind of exchange-worthy goods that are used by male society. The existence of individuals as individuals is absent. In the feudal era, the patriarchal culture with the feudal ethics as the outer garment advocated "the words of the parents, the words of the media," and women still did not have independent love and marriage [4]. After the May 4th Movement, the liberation of people allowed new women to bravely pursue the freedom of love and the liberation of sex. However, women's pursuit of love is very difficult. On the one hand, men's most liberating liberation and love freedom have caused damage to women. The original wife, represented by traditional women, has been abandoned and new women have become The third party faces the entanglement of love and morality. On the other hand, it is still difficult for women to shake off the influence of the patriarchal culture for thousands of years, and it is still difficult to get rid of the psychological attachment to men. This point has been described in detail in the previous article. Then, how should women face love? Both traditional women and new women should maintain a rational attitude. When love comes, they should invest but don't blindly. Always leave women's self-esteem and independent love to walk away. In the face of it, do not blame yourself, and be more active in your life. When love came, it was vigorous and vigorous. Women were easily trapped in this love and could not extricate themselves, but the females in Yang Jiang's writing still did not lose their reason. As a representative of Yang Jiang's early career in the literary world, Yang Xi used a delicate and lightweight technique possessed by a young woman and a keen eye of a female university student to present a woman with optimistic and open-minded spirit in her future. Hey. The female college student who is full of passion for life has an ambivalence between ideals and worldliness in the face of affection. Tom must be tall and handsome, but his family is not good and his future is uncertain. The key character is not suitable for himself. In general, the family is well-off, the future is great, and the character is also suitable for themselves. Among the two men, if they accept soup, they must endure hardship. Accepting Xiao Wang is not a matter of personal preference. Both are not good choices. While he was circling around the two men, but with the girl's reservedness and tweaking, eventually the soup would have gone, and Xiaowang was also married to his cousin. This "two emotions" were defeated. However, she is not as frustrated and sentimental as an ordinary girl in love, but actively pursues a new life of self-reliance. When she learns that there is a response to studying in the United States free of charge, she will "smile and gently relax. In a breath." Although she is a young girl, whether she is feeling her love or studying abroad, she leads and manipulates her life with a completely active attitude, and she can also maintain her rational scrutiny in the face of feelings. Not falling into a worldly choice is a rich one, and there is no vortex for love to fall into

emotion. So in the end, when emotions are frustrated, they can quickly transfer to school. From the skeleton, we can see that Yang Xie's feminine consciousness has been revealed at such a young age [5].

\section{Conclusion}

Yang Jiang not only achieved a complete family life, but also achieved success in her academic career. Her successful breakthrough in the role of family and career has not only provided a 
reference and a way out for the current intellectual woman, but also contributed to her success. The development and reflection of the women's liberation movement has provided a valuable research model.

\section{Acknowledgment}

Project Fund: "13th Five-Year Plan" Science and Technology Research Project of the Education Department of Jilin Province

Contract No.: JJKH20170356SK

\section{References}

[1] Liu Meizhu. Two correspondences between Mr. Yang Jiang and Liu Meizhu [J]. Studies in Chinese Literature. 2006 (01)

[2] Shi Yongxiu. On the Female Images in Yang Xie's Novel "Bathing" [J]. Jiangxi Social Sciences. $2003(02)$

[3] Liu Meizhu. Two correspondence between Mr. Yang Jiang and Liu Meizhu [J]. Chinese Literature Studies. 2006 (01)

[4] Shi Yongxiu. On the Female Images in Yang Jiang's Novel "The Bath" [J]. Jiangxi Social Sciences. 2003 (02)

[5] Du Yun. Study of Han Suyin's "Treasure" from the Perspective of Feminism [D]. Shanxi Normal University. 2012 